\title{
Uji kesetimbangan kalor proses sterilisasi kumbung jamur merang kapasitas 1.2 ton media tanam menggunakan tungku gasifikasi
}

\author{
Ahmad Maulana K'), Aa Setiawan ${ }^{2)}$ \\ Jurusan Teknik Pendingin dan Tata Udara, Politeknik Negeri Indramayu ${ }^{1 / 2)}$ \\ JI. Raya Lohbener lama No.08 - Indramayu, Jawa Barat \\ ahmedmaulana21@yahoo.co.id, ${ }^{1}$ atilawaone@yahoo.co.id ${ }^{2}$
}

\begin{abstract}
Abstrak
Pada setiap budidaya jamur merang memerlukan proses sterilisasi dengan menggunakan uap panas yang dihasilkan dari boiler sederhana dengan tungku tradisional berbahan bakar kayu bakar. Penggunaan tungku tradisional pada aplikasi proses sterilisasi tersebut dinilai kurang efisien karena efisiensi pembakaran yang masih sangat rendah dan emisi gas buang yang mengganggu. Tungku gasifikasi memiliki kinerja yang lebih baik dari pada tungku tradisional karena memiliki efisiensi yang relatif lebih tinggi dan bebas dari asap pembakaran yang mengganggu. Untuk menggantikan tungku tradisional tersebut dengan tunggku gasifikasi, harus dilakukan uji kesetimbangan kalor terlebih dahulu agar dapat diketahui kebutuhan energi yang diperlukan pada proses sterilisasi tersebut. Dengan uji kesetimbangan kalor dapat diketahui perbandingan energi input pada sisi bahan bakar dengan energi yang termanfaatkan (energi output) dan energi yang terbuang (heat losses) selama proses sterilisasi tersebut berlangsung. Pengujian dilakukan dengan menggunakan kumbung jamur ukuran sebenarnya yang ada di lapangan dengan jumlah media tanam jamur merang sekitar 1.2 ton limbah kapas menggunakan tungku gasifikasi yang dibuat dari drum bekas oli. Pengujian dilakukan dengan dua variasi bahan bakar pada reactor gasifikasinya yaitu bahan bakar limbah kapas dan bahan bakar limbah sekam padi. Dari hasil uji yang didapat, limbah kapas memiliki jumlah energi output yang lebih besar daripada limbah sekam padi (energi output pada limbah kapas sebesar 8.4\% dari energi inputnya dan limbah sekam padi memiliki 7.9\% energi output). Namun jika dilihat dari efisiensi pembakarannya, limbah sekam padi memiliki efisiensi yang lebih tinggi daripada limbah kapas $(28.0 \%$ untuk limbah sekam padi dan $27.2 \%$ untuk limbah kapas).
\end{abstract}

Kata kunci: sterilisasi, kesetimbangan kalor, efisiensi

\section{Pendahuluan}

Jamur merang merupakan salah satu jenis spesies tanaman yang paling banyak di budidayakan di Indonesia, khususnya di daerah Karawang Jawa Barat. Sudah sejak lama, kabupaten ini telah ditetapkan menjadi sentra jamur merang nasional dengan jumlah petaninya yang mencapai lebih dari 4.000 petani [1]. Jamur merang dibudidayakan dengan cara ditanam diatas media tanam yang berupa limbah kapas, limbah jerami, dan atau limbah kardus yang telah difermentasi terlebih dahulu. Media tanam jamur tersebut ditempatkan pada sebuah kumbung (rumah) jamur yang terbuat dari dinding plastik dan stirofoam dan rangkanya terbuat dari bambu.
Proses sterilisasi kumbung jamur merang biasanya dilakukan oleh para petani jamur sebelum penanaman benih dilakukan pada media tanam yang berupa limbah kapas atau limbah jerami atau limbah kardus tersebut. Proses sterilasi tersebut penting dilakukan agar media tanam bebas dari hama atau bakteri yang mengganggu pertumbuhan jamur merang itu sendiri. Pada proses sterilisasi, temperatur kumbung jamur merang dijaga pada kondisi temperatur 70 $80{ }^{\circ} \mathrm{C}$ dan dipertahankan hingga sekitar 4-6 jam lamanya proses tersebut berlangsung. Sistem pemanas yang digunakan oleh para petani jamur merang tersebut umumnya menggunakan boiler tungku tradisional 
berbahan bakar kayu bakar. Penggunaan tungku tradisional pada aplikasi proses sterilisasi kumbung jamur tersebut dinilai kurang efisien karena efisiensi pembakaran yang masih sangat rendah (berkisar antara 5 - 10\%) dan emisi gas buang yang mengganggu lingkungan sekitar [2]. Beberapa kendala yang dimiliki tungku tradisional tersebut sebenarnya dapat diatasi dengan menggunakan tungku gasifikasi.

Pengujian performansi tungku gasifikasi untuk proses sterilisasi kumbung jamur merang kapasitas kecil (kapasitas $\pm 35 \mathrm{~kg}$ media tanam) telah dilakukan dengan menggunakan tungku gasifikasi UB-03 sebagai pengganti tungku tradisional dengan menggunakan bahan bakar limbah media tanam jamur merang. Pada pengujian tersebut didapat efisiensi pembakaran sekitar $21.7 \%-27.2 \%$ [3]. Nilai efisiensi ini jauh lebih tinggi bila dibandingkan dengan efisiensi pada tungku tradisional yang hanya berkisar $5-10 \%$ saja. Untuk dapat menerapkan tungku gasifikasi pada proses sterilisasi sebenarnya yang ada di lapangan dibutuhkan analisa kesetimbangan energy lebih lanjut pada model tungku gasifikasi tersebut. Dengan analisa kesetimbangan energy pada proses sterilisasi tersebut, dapat diketahui berapa persen energy panas yang dibutuhkan baik pada sisi ruangan (energi output) maupun pada sisi ruang pembakaran (energy input bahan bakar) yang digunakan. Dengan demikian, ukuran tungku gasifikasi yang sesuai dengan kebutuhan energy total pada proses sterilisasi tersebut dapat ditentukan kemudian dengan mudah.

Untuk itu dalam penelitian kali ini, akan dibuat dan di uji kesetimbangan kalor penggunaan tungku gasifikasi kapasitas besar yang sesuai dengan kebutuhan sterilisasi kumbung sebenarnya yang ada di lapangan. Ukuran kumbung jamur merang yang ada tersebut adalah sekitar $7 \times 5 \times 4 \mathrm{~m}$, dengan isi media tanam jamur merang sebanyak 1.2 ton $(1200 \mathrm{~kg})$ limbah kapas. Temperatur yang ingin di capai pada pengujian tersebut adalah sekitar $70-80{ }^{\circ} \mathrm{C}$ pada ruangan kumbungnya.

\section{Tinjauan Teoritis}

Prinsip sederhana dari proses sterilisasi kumbung dengan menggunakan tungku gasifikasi tersebut sebenarnya adalah merupakan serangkaian proses perubahan/perpindahan kalor dari energi bahan bakar biomassa menjadi energi uap panas dan kemudian dipindahkan ke ruangan kumbung dan media tanam jamur. Proses ini dapat dianggap sebagai proses transfer kalor yang sesuai dengan konsep kesetimbangan energi pada boiler.

Analisa kesetimbangan kalor pada boiler berguna untuk memperkirakan nilai nilai kalor yang terbuang dan yang terpakai pada tiap sisi proses perpindahan panas yang terjadi selama proses sterilisasi tersebut. Analisa kesetimbangan energi diawali dari energi kalor biomassa yang digunakan sebagai bahan bakar $\left(Q_{\text {fuel }}\right)$ sebagai energi input, energi kalor pada air $\left(\mathrm{Q}_{\mathrm{H} 2 \mathrm{O}}\right)$ dan sampai pada energi kalor / beban pemanasan media tanam $\left(Q_{\text {load }}\right)$ pada kumbung sebagai energi output. Hal ini dilakukan untuk mengetahui seberapa besar potensi energi yang dihasilkan pada sisi akhir outputnya bila dibandingkan dengan energi total inputnya. Adapun skema umum dari kesetimbangan energi yang ada pada boiler untuk proses sterilisasi kumbung jamur merang adalah seperti terlihat pada gambar berikut [2] :

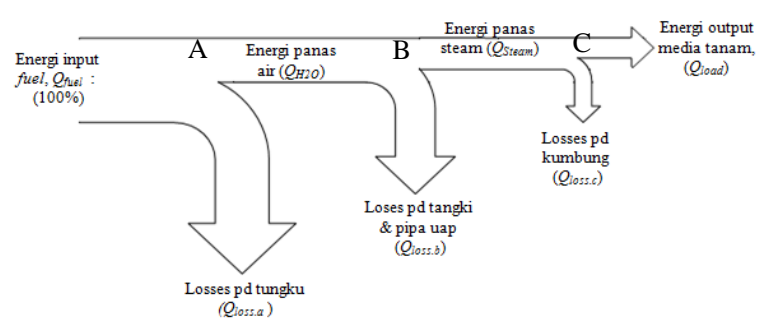

Gambar 1. Skema neraca energi pada proses sterilisasi kumbung jamur merang.

Terlihat pada gambar diatas bahwa energi input yang berasal dari bahan bakar biomassa tersebut mengalami perpindahan sebanyak tiga kali, yaitu perpindahan energi pada sisi reaktor pembakaran (sisi a), pada sisi aliran uap (sisi b) dan pada sisi kumbung (sisi c). Selama proses perpindahan energi 
tersebut terdapat energi buang (heat losses) yang tidak termanfaatkan sehingga jumlah efisiensinya juga sebanyak tiga kali. Dan untuk menghitung efisiensi total dari tungku gasifikasi pada proses sterilisasi tersebut dengan menjumlahkan ketiga efisiensi yang ada tersebut.

Eff. total $=$ eff. $\mathrm{a} \times$ eff. $\mathrm{b} \times$ eff. $\mathrm{c}$

\section{Dimana :}

eff. total = effisiensi keseluruhan proses

eff. $\mathrm{a}=$ effisiensi pada ruang pembakaran

eff. $\mathrm{b}=$ effisiensi pada tangki air, saluran uap

eff. $\mathrm{c}=$ effisiensi pada sisi kumbung

Adapun rumus yang digunakan untuk menentukan efisiensi total sesuai dengan skema kesetimbangan energi diatas adalah sebagai berikut [3].

Efisiensi total $=\frac{Q_{\text {output }}}{Q_{\text {input }}}=\frac{Q_{\text {load }}}{Q_{\text {fuel }}}$

Q output $\quad=$ Q input $-\sum \mathrm{Q}$ losses

$\sum \mathrm{Q}$ losses $=\mathrm{Q}$ loss $\mathrm{a}+\mathrm{Q}$ loss $\mathrm{b}+\mathrm{Q}$ loss c (4)

Dimana :

$\sum \mathrm{Q}$ losses $=$ rugi kalor keseluruhan proses

$\mathrm{Q}$ loss a $=\underset{\text { pembakaran }}{\text { rugi kalor pada ruang }}$

$\mathrm{Q}$ loss $\mathrm{b}=$ rugi kalor pada tangki, saluran uap

$\mathrm{Q}$ loss $\mathrm{c}=$ rugi kalor pada sisi kumbung

Potensi energi kalor yang terkandung pada bahan bakar biomassa (energi input) tersebut dapat dihitung dengan menggunakan rumus berikut ini, yaitu [4] :

$$
Q_{\text {fuel }}=m \times H H V
$$

Dimana :

$Q_{\text {fuel }}=$ jumlah kalor hasil pembakaran bahan bakar biomassa, $(\mathrm{kJ})$

$m$ = massa bahan bakar biomassa yang

$$
\begin{aligned}
& \text { terbakar selama pembakaran, }(\mathrm{kg}) \\
& H H V=\text { nilai kalor pembakaran bahan } \\
& \text { bakar biomassa tiap satuan massa, } \\
& (\mathrm{kJ} / \mathrm{kg})
\end{aligned}
$$

Berdasarkan rumus tersebut diatas, untuk menghitung jumlah kalor pembakaran bahan bakar, maka diperlukan nilai kalor pembakaran bahan bakar (HHV) yang digunakannya. Untuk limbah kapas berdasarkan hasil uji di laboratorium Jurusan teknik Mesin Universitas Udayana, memiliki nilai kalor (HHV) sebesar 15355 kJ/kg.K [3]. Dan untuk limbah sekam padi, berdasarkan hasil uji di laboratorium juga di Jurusan Teknik Mesin Universitas Udayana didapat nilai kalor (HHV) sebesar 13784 kJ/kg.K [5].

Untuk menghitung jumlah kalor yang diterima pada sisi air adalah dengan menghitung jumlah kalor pemanasan sensibel dan penguapan latennya. Untuk menghitung laju kalor sensibel pada air dapat menggunakan persamaan asas Black, sedangkan untuk menghitung kalor latennya adalah dengan cara mengalikan nilai kalor laten penguapan air dengan massa uap yang terbentuk, yaitu :

$$
\begin{aligned}
& Q_{S H 2 O}=m_{H 2 O} c p_{H 2 O}\left(T_{2}-T_{1}\right) \ldots \ldots \\
& Q_{\text {steam }}=m_{\text {steam }} x H_{f g} \ldots \ldots \ldots \ldots(7)
\end{aligned}
$$

$$
Q_{H 2 O}=Q_{S H 2 O}+Q_{\text {steam }}
$$

\section{Dimana :}

$$
\begin{aligned}
& Q_{S H 2 O}=\text { jumlah kalor sensible yang } \\
& \text { terpakai untuk } \\
& \text { memanaskan air }(\mathrm{kJ}) \\
& Q_{\text {steam }}=\text { jumlah kalor laten yang } \\
& \text { terpakai untuk } \\
& \text { menguapkan air }(\mathrm{kJ}) \\
& Q_{H 2 O}=\text { jumlah kalor total air }(\mathrm{kJ}) \\
& m_{H 2 O}=\text { massa air yang dipanaskan, }(\mathrm{kg}) \\
& m_{\text {steam }}=\text { massa air yang berubah menjadi } \\
& \text { uap, }(\mathrm{kg}) \\
& c p_{H 2 O}=\text { kalor jenis air, }\left(=4,19 \mathrm{~kJ} / \mathrm{kg}^{\circ} \mathrm{C}\right) \\
& T_{1} \quad=\text { temperatur air pada kondisi awal } \\
& \text { (kondisi lingkungan), }\left({ }^{\circ} \mathrm{C}\right) \\
& T_{2} \quad=\text { temperatur air pada kondisi }
\end{aligned}
$$




$$
\begin{aligned}
& \text { akhir, }\left({ }^{\circ} \mathrm{C}\right) \\
& =\mathrm{kalor} \text { laten penguapan air, }(=334 \\
& \mathrm{kJ} / \mathrm{kg})
\end{aligned}
$$

Selanjutnya, untuk menghitung jumlah kalor pada sisi media tanam (kapas) adalah dengan menggunakan persamaan asas Black, mengingat pada media tanam tersebut hanya mengalami proses pemanasan sensibel saja. Berikut ini adalah persamaan asas Black yang digunakan untuk menghitung kalor sensibel media tanam tersebut yaitu :

$$
Q_{\text {load }}=m_{\text {kapas }} c p_{\text {kapas }}\left(T_{2}-T_{1}\right) \ldots \ldots
$$

Dimana :

$$
\begin{aligned}
& Q_{\text {load }}=\text { jumlah kalor sensible yang } \\
& \text { terpakai untuk } \\
& \text { memanaskan media tanam } \\
& \text { (kapas) (kJ) } \\
& m_{\text {kapas }}=\text { massa kapas yang dipanaskan, } \\
& (\mathrm{kg}) \\
& c p_{\text {kapas }}=\text { kalor jenis rata }- \text { rata kapas, }(1.34 \\
& \mathrm{kJ} / \mathrm{kg} \cdot \mathrm{K} \text { ) } \\
& T_{1} \quad=\text { temperatur rata }- \text { rata kapas pada } \\
& \text { kondisi } \\
& \text { awal (kondisi lingkungan), }\left({ }^{\circ} \mathrm{C}\right) \\
& T_{2}=\text { temperatur rata }- \text { rata kapas pada } \\
& \text { kondisi akhir, }\left({ }^{\circ} \mathrm{C}\right)
\end{aligned}
$$

Untuk menghitung beban pemanasan media tanam tersebut dibutuhkan data kalor jenis (cp) media tanam yang digunakan / di panaskan, yang dalam hal ini adalah berupa limbah kapas. Kapas tersebut berdasarkan pada tabel nilai kalor jenis pada web engineeringtoolbox didapat nilai kalor jenis sebesar $1,34 \mathrm{~kJ} / \mathrm{kg} .{ }^{\circ} \mathrm{C}[6]$. Dan karena media tanam (kapas) tersebut kondisinya basah / campur air dimana kadar airnya bisa mencapai $50 \%$, maka nilai kalor jenisnya pun merupakan nilai kalor jenis rata - rata penjumlahan antara kalor jenis air dan kalor jenis kapas. Didapat nilai kalor jenis rata rata kedua bahan media tanam tersebut (kapas + air) adalah sekitar 2,75 kJ/kg. ${ }^{\circ} \mathrm{C}$.

\section{Metode Penelitian}

Penelitian ini dimulai dengan terlebih dahulu membuat tungku gasifikasi dengan ukuran disesuaikan dengan bahan baku yang ada di pasaran. Bahan baku tungku gasifikasi yang digunakan adalah berupa 2 buah drum besi bekas oli dengan diameter $48 \mathrm{~cm}$ dan $60 \mathrm{~cm}$. Tinggi dari drum bekas oli tersebut adalah sekitar $90 \mathrm{~cm}$. Selanjutnya bahan baku tungku drum besi tersebut dibuat tungku gasifikasi sesuai dengan desain seperti terlihat dibawah ini.

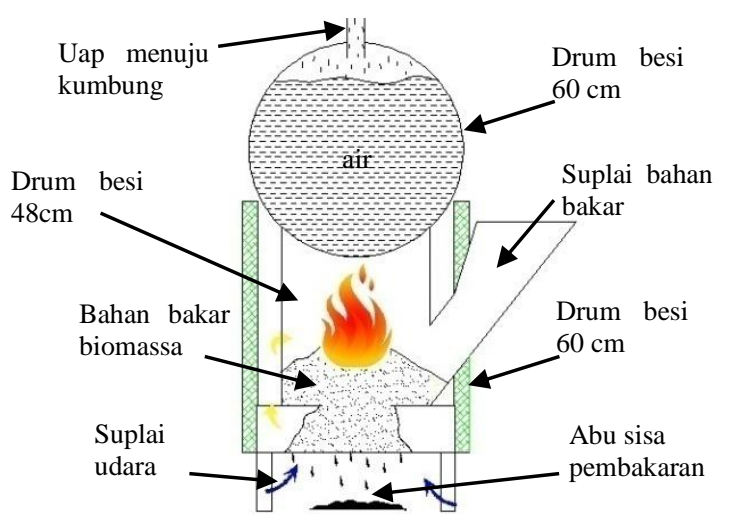

Gambar 2. Rancangan tungku gasifikasi untuk proses sterilisasi kumbung jamur merang

Desain dari tungku gasifikasi tersebut dibuat sedemikian rupa untuk dapat membakar bahan bakar biomassa (sekam dan limbah kapas) tanpa dibuat briket terlebih dahulu. Pemilihan kedua bahan bakar biomassa tersebut dilakukan mengingat limbah kapas dan sekam tersedia melimpah di sekitar lokasi kumbung jamur merang sebagai hasil samping (buangan) dari proses budidaya jamur merang itu sendiri. Selain itu juga kedua jenis bahan bakar biomassa tersebut memiliki nilai kalor yang berbeda cukup jauh, sehingga kedua jenis bahan bakar tersebut dapat dijadikan perbandingan pada pengujian ini. Tungku gasifikasi yang dibuat merupakan jenis updraft sistem dimana bahan bakar disuplai dari samping sebelah atas dari tungku dan suplai udara pembakaran berada pada bagian bawah tungku.

Setelah tungku gasifikasi selesai dibuat, langkah selanjutnya adalah menyiapkan bahan bakar biomassa yang akan dijadikan bahan bakar pada tungku gasifikasi tersebut. Bahan bakar yang digunakan adalah berupa 
limbah kapas hasil sisa media tanam jamur merang dan limbah sekam padi hasil sisa tanaman padi. Khusus untuk limbah kapas karena kondisinya yang basah, maka perlu dijemur di bawah sinar matahari terlebih dahulu selama 3 hari agar kondisinya benar benar kering dan dapat digunakan sebagai bahan bakar tungku gasifikasi. Setelah itu dilakukan pengujian proses sterilisasi kumbung jamur merang menggunakan tungku gasifikasi yang telah dibuat dengan bahan bakar yang telah siap digunakan.

Proses sterilisasi kumbung jamur merang dimulai dengan memanaskan air yang ada di dalam drum besi penampung air yang terdapat pada bagian atas tungku gasifikasi. Air yang dipanaskan akan mengalami kenaikan temperatur sampai pada titik jenuh $\left(100{ }^{\circ} \mathrm{C}\right)$ dan dipanaskan lebih lanjut hingga air tersebut berubah fasa menjadi uap panas pada temperatur tetap 100 ${ }^{\circ} \mathrm{C}$. Uap panas tersebut kemudian dialirkan melalui pipa menuju ruangan kumbung hingga mengakibatkan temperatur udara pada kumbung tersebut mengalami kenaikan. Akibat kenikan temperatur udara pada kumbung tersebut, maka temperatur media tanam juga mengalami kenaikan. Kenaikan temperatur kumbung dibatasi hanya sampai temperatur $70{ }^{\circ} \mathrm{C}$ saja dan dijaga selama waktu 4 jam lamanya. Media tanam jamur merang yang ada di dalam kumbung tersebut adalah berupa limbah kapas sisa produksi textile sebanyak $\pm 1200 \mathrm{~kg}$ (1.2 ton).

Pengujian dilakukan sebanyak 2 (dua) kali dengan bahan bakar yang berbeda. Pengujian yang pertama menggunakan bahan bakar limbah kapas dan yang kedua menggunakan limbah sekam padi. Selama pengujian berlangsung, dilakukan pengambilan beberapa data temperatur yang ada pada sistem guna mengetahui performansi dari tungku gasifikasi tersebut. Jenis temperatur yang terdapat pada proses sterilisasi tersebut terdiri dari : temperatur air, temperatur uap, temperatur kumbung, dan temperatur media tanam pada kumbung. Keempat titik temperatur tersebut diukur dengan menggunakan termokopel yang terhubung dangan data akuisisi type KTE
DA100 dan langsung menampilkan datanya pada perangkat komputer/laptop. Data temperatur yang terbaca pada komputer tersebut kemudian akan tercatat pada Tabel excel setiap 1 menit sekali secara otomatis.

Sebuah timbangan digital juga digunakan untuk mengetahui jumlah massa bahan bakar biomassa yang disuplai pada ruang pembakaran sehingga dapat diketahui jumlah bahan bakar yang terpakai selama pembakaran berlangsung. Data tentang massa bahan bakar biomassa tersebut tercatat tersendiri secara manual pada Tabel yang lain. Berikut ini merupakan skema proses pengujian yang dilakukan pada kumbung jamur merang milik salah satu petani jamur merang yang ada di Indramayu.

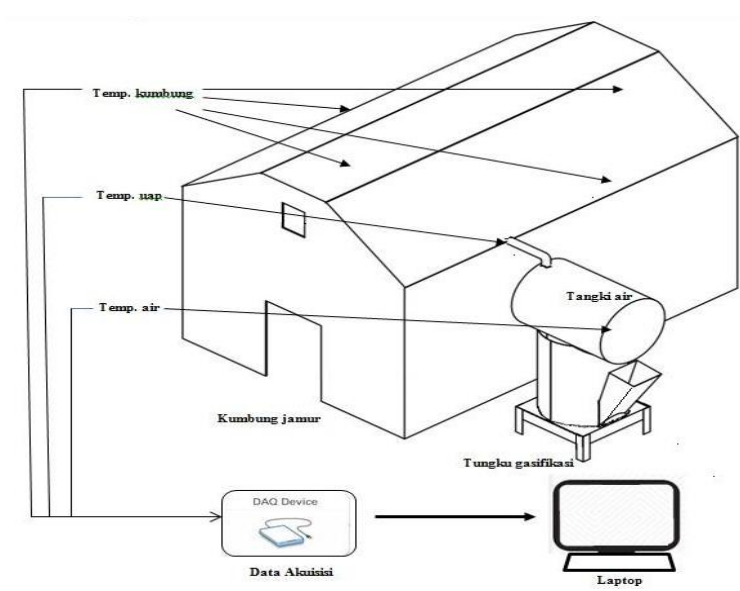

Gambar 3. skema pengujian uji kesetimbangan kalor pada proses sterilisasi kumbung jamur merang

\section{Hasil dan Pembahasan}

Tabel 1 berikut ini adalah tabel singkat yang berisi data temperatur hasil resume dari tabel yang dihasilkan oleh data akuisisi. Sedangkan tabel 2 merupakan tabel hasil pengolahan data lebih lanjut untuk menghitung kesetimbangan kalor yang terjadi selama proses sterilisasi berlangsung. 
Tabel 1. Resume data hasil pengujian

\begin{tabular}{|c|l|c|c|}
\hline \multirow{2}{*}{ No } & \multicolumn{1}{|c|}{ Parameter data } & \multicolumn{2}{|c|}{$\begin{array}{c}\text { Jenis Bahan } \\
\text { bakar }\end{array}$} \\
\cline { 3 - 4 } & & Kapas & Sekam \\
\hline 1 & $\begin{array}{l}\text { Waktu operasi sterilisasi } \\
\text { total (min) }\end{array}$ & 155 & 147 \\
\hline & $\begin{array}{l}\text { Waktu pemanasan } \\
\text { sensibel (min) }\end{array}$ & 62 & 74 \\
\hline 2 & $\begin{array}{l}\text { Waktu pemanasan } \\
\text { laten (min) }\end{array}$ & 93 & 73 \\
\hline 3 & $\begin{array}{l}\text { Jumlah bahan bakar } \\
\text { terpakai (kg) }\end{array}$ & 20.96 & 22.28 \\
\hline 4 & $\begin{array}{l}\text { Nilai HHV Bahan bakar } \\
\text { Jumlah energi bahan } \\
\text { bakar Q fuel (MJ) }\end{array}$ & 15355 & 13784 \\
\hline 5 & $\begin{array}{l}\text { Temperatur kumbung } \\
\text { tercapai }\left({ }^{\circ} \mathrm{C}\right)\end{array}$ & 49 & 467.84 \\
\hline 6 & $\begin{array}{l}\text { Temp. media tanam } \\
\text { (kapas) rata2 }\left({ }^{\circ} \mathrm{C}\right)\end{array}$ & 39.3 & 37.5 \\
\hline
\end{tabular}

Terlihat pada tabel 1 diatas perbedaan bahan bakar pada proses sterilisasi akan mengakibatkan performansi sistem berbeda pula. Hal ini disebabkan oleh nilai kalor masing - masing bahan bakar tersebut berbeda pula dimana nilai HHV kapas sebesar $15355 \mathrm{~kJ} / \mathrm{kg}$ sedangkan nilai $\mathrm{HHV}$ sekam padi sebesar $13784 \mathrm{~kJ} / \mathrm{kg}$. Dengan nilai kalor yang cukup besar tersebut, bahan bakar kapas hanya membutuhkan 20.96 kg untuk memanaskan kumbung jamur merang pada temperatur $49{ }^{\circ} \mathrm{C}$, sedangkan bahan bakar sekam padi sejumlah $22.28 \mathrm{~kg}$ hanya mampu memanaskan kumbung jamur merang hingga temperatur $46{ }^{\circ} \mathrm{C}$. Demikian juga dengan temperatur media tanam jamur rata - rata pada bahan bakar kapas dapat tercapai lebih tinggi dibandingkan bahan bakar sekam padi yaitu tercapai pada temperatur $39.3{ }^{\circ} \mathrm{C}$ sedangkan pada sekam padi hanya sebesar $37.5{ }^{\circ} \mathrm{C}$ saja. Namun berbeda dengan efisiensi pembakaran yang cenderung lebih kecil pada bahan bakar limbah kapas bila di bandingkan dengan sekam padi (lihat Tabel 2 berikut). Efisiensi pembakaran pada bahan bakar limbah kapas hanya sebesar $27.2 \%$ sedangkan pada bahan bakar sekam padi dapat mencapai $28.0 \%$. Hal ini menunjukkan bahwa semakin besar nilai kalor bahan bakar, maka akan mengakibatkan semakin banyak kalor yang terbuang sehingga efisiensi pembakarannya semakin kecil.

Terlihat pada Tabel 2 juga, bahwa jumlah energi output yang terpakai untuk memanaskan media tanam jamur merang (kapas) yang berada di dalam kumbung tersebut sedikit sekali nilainya yaitu hanya sekitar $7.9 \%-8.4 \%$ saja dari total energi inputnya. Hal ini menunjukkan masih banyak energi kalor yang terbuang ke lingkungan dan tidak termanfaatkan. Masih banyak faktor yang perlu dibenahi pada proses sterilisasi tersebut agar energi input tidak banyak terbuang percuma. Energi yang banyak terbuang terdapat pada bagin tungku pembakaran dan juga pada bagian saluran penampung air dan uap dimana (sisi A dan sisi B pada skema kesetimbangan energi). Pada bagian pembakaran (sisi A) efisiensinya hanya sebesar $27.2 \%$ (untuk bahan bakar kapas) hal ini dikarenakan masih banyaknya celah pada ruang pembakaran sehingga banyak panas pembakaran yang terbuang ke lingkungan. Dan pada bagian saluran penampung air dan uap (sisi B) efisiensinya juga rendah hanya sebesar $35.5 \%$ dikarenakan banyak energi dari air panas yang tidak seluruhnya berubah menjadi uap sehingga tidak dapat dimanfaatkan (terbuang ke lingkungan). Jika seluruh air panas pada tangki penampung tersebut berubah menjadi uap, maka nilai efisiensi pada sisi B ini akan meningkat jauh dari nilai saat ini. 
Tabel 2. Perhitungan energi kalor pada proses sterilisasi

\begin{tabular}{|c|c|c|c|}
\hline \multirow{2}{*}{ No } & \multirow{2}{*}{ Parameter perhitungan } & \multicolumn{2}{|c|}{ Jenis bahan bakar } \\
\hline & & kapas & sekam \\
\hline \multirow[t]{6}{*}{1} & Kondisi air : & & \\
\hline & temp awal, $\mathrm{T}$ air.aw $\left({ }^{\circ} \mathrm{C}\right)$ & 31 & 31 \\
\hline & temp akhir, $\mathrm{T}$ air.ak $\left({ }^{\circ} \mathrm{C}\right)$ & 100 & 100 \\
\hline & massa air awal $(\mathrm{kg})$ & 195 & 195 \\
\hline & massa air akhir $(\mathrm{kg})$ & 102 & 107 \\
\hline & massa uap $(\mathrm{kg})$ & 93 & 88 \\
\hline 2 & $\begin{array}{l}\text { Energi kalor sensibel, Q S H2O } \\
(\mathrm{MJ})\end{array}$ & 56.51 & 56.51 \\
\hline 3 & Energi kalor laten, Q steam $(\mathrm{MJ})$ & 31.06 & 29.39 \\
\hline 4 & Energi kalor total air, Q H2O (MJ) & 87.57 & 85.90 \\
\hline 5 & Energi kalor total bahan bakar (MJ) & 321.84 & 307.11 \\
\hline 6 & Eff. Tungku, $\eta$ a (\%) & 27.2 & 28.0 \\
\hline 7 & Effisiensi pipa uap, $\eta$ b (\%) & 35.5 & 32 \\
\hline \multirow[t]{5}{*}{8} & $\begin{array}{l}\text { Kondisi media tanam jamur (kapas) } \\
:\end{array}$ & & \\
\hline & massa $(\mathrm{kg})$ & 1200 & 1200 \\
\hline & kalor jenis $\left(\mathrm{kJ} / \mathrm{kg} .{ }^{\circ} \mathrm{C}\right)$ & 2.75 & 2.75 \\
\hline & temp awal, $\mathrm{T}$ rt2.aw $\left({ }^{\circ} \mathrm{C}\right)$ & 31.0 & 31.0 \\
\hline & temp akhir, T rt2.ak $\left({ }^{\circ} \mathrm{C}\right)$ & 39.3 & 38.5 \\
\hline 9 & Energi kalor total media kapas (MJ) & 26.89 & 24.30 \\
\hline 10 & Energi kalor laten air, Q steam (MJ) & 31.06 & 29.39 \\
\hline 11 & Effisiensi kumbung, $\eta \mathrm{c}(\%)$ & 86.6 & 82.5 \\
\hline 12 & $\begin{array}{l}\text { Effisiensi total, } \eta \text { tot (output/input), } \\
\%\end{array}$ & 8.4 & 7.9 \\
\hline
\end{tabular}

Berikut ini merupakan contoh skema nilai kesetimbangan energi yang terjadi selama proses sterilisasi kumbung jamur merang, yaitu :

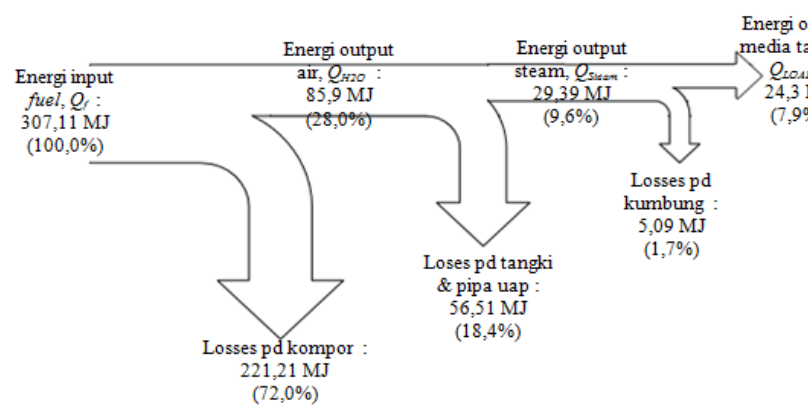

Gambar 4. Skema nilai kesetimbangan energi proses sterilisasi berbahan bakar sekam padi

Terlihat pada gambar 4 dan sesuai dengan tabel 2 diatas bahwa nilai energy yang tidak terpakai (heat loss) paling banyak terdapat pada tungku pembakaran dan pada tangki air. Jumlah heat loss tersebut sekitar 221,21 MJ pada tungku pembakaran dan 56,51 MJ pada tangkai air. Jumlah kedua losses tersebut mencapai 277,72 MJ (90,4\% dari energi inputnya) sementara jumlah energi yang terpakai untuk memanaskan kumbung jamur merang hanya sekitar 24,30 MJ (7.9\% dari energi inputnya).

\section{KESIMPULAN}

Berdasarkan pada percobaan yang telah dilakukan tersebut, dapat diambil beberapa kesimpulan seperti berikut ini, yaitu :

1.Temperatur kumbung jamur merang yang dapat dicapai pada pengujian tersebut adalah sebesar $49^{\circ} \mathrm{C}$ untuk bahan bakar limbah kapas dan $46^{\circ} \mathrm{C}$ untuk bahan bakar sekam padi.

2.Untuk nilai efisiensi total proses sterilisasi tersebut sekitar $7.9 \%$ menggunakan bahan bakar sekam padi dan $8.4 \%$ dengan menggunakan bahan bakar limbah kapas. Dimana jumlah energi yang terpakai untuk memanaskan kumbung jamur merang tersebut sekitar $24.30 \quad$ MJ menggunakan bahan bakar sekam padi dan 26.89 MJ dengan bahan bakar limbah kapas.

3.Jumlah heat loss yang paling banyak terdapat pada tungku pembakaran dan pada tangki air dimana nilai persentase heat loss pada kedua bagian tersebut dapat mencapai 90,4\% dari total energi inputnya atau sekitar 277,72 MJ menggunakan bahan bakar sekam padi.

\section{DAFTAR PUSTAKA}

[1]. Information on http:www.kabarrakyat.com

[2]. Winata, Resiana. Perancangan Kompor Biomassa. Skripsi Jurusan Teknik Kimia, Universitas Indonesia. Depok. 2012.

[3]. Maulana K, Ahmad. Uji performansi gasifikasi biomassa pada proses 
sterilisasi berbahan bakar limbah media tanam jamur merang. Tesis Jurusan Magister Teknik Mesin Universitas Udayana. Denpasar, Bali. 2015.

[4]. Keating, Eugene L. Applied combustion, Second Edition. Taylor \& Francis Group, LLC. New York USA. 2007.

[5]. Krisna P, Gusti Ngurah. Performansi kompor biomassa sekam padi dengan memvariasikan saluran api dan katup udara pembakaran. Skripsi Jurusan Teknik Mesin Universitas Udayana. Denpasar, Bali. 2013.

[6]. Information on http:www.engineeringtoolbox.com/ specific-heat-solids-d_154.html 